\section{WHAT HAPPENS IF THE NEIGHBOR'S MEDICATION IS USED? ACCIDENTAL INTOXICATION DUE TO FENTANYL TRANSDERMAL PATCH}

To the editor:

A 61-year-old, 90-kg female patient who was brought to the emergency room because of unconsciousness and respiratory difficulty is presented. After the exclusion of neurologic pathologies by a cranial computed tomography scan, she was transferred to the intensive care unit (ICU) for followup. At the ICU, when her clothes were removed, it was seen that there were eight pieces of Durogesic ${ }^{\circledR} 50 \mu \mathrm{g}$ transdermal therapeutic system patches on various parts of the body (two patches on both knees, two patches on thighs, two patches on back, two patches on the ankles). The patches were removed from her body, and the skin was cleaned. With these findings, opioid intoxication was suspected, and the diagnosis was confirmed by empiric administration of $0.4 \mathrm{mg}$ naloxone. The patient was weaned from the mechanical ventilator and extubated after eight hours. Further inquiry with the patient revealed that her neighbor, whose uncle died after having an oncologic disease, gave these patches and advised her to use these powerful analgesic patches for her pain. The patient then attached the patches to the aching parts of her body. Following extubation, she was supervised in the ICU for 48 hours and then discharged from the hospital with no sequelae.

Fentanyl transdermal delivery patches are often used in patients with chronic cancer pain and they are also increasingly being prescribed in the management of moderate-to-severe noncancer pain. The United States Food and Drug Administration emphasized that, even the amount of drug in one lowest-dose fentanyl patch is large enough to cause fatal respiratory depression in patients who are opioid-naïve. ${ }^{1}$ After attaching the transdermal delivery patch, it delivers the drug at a constant rate and achieves steady plasma levels over 72 hours, which makes it well suited for the management of chronic severe pain. High lipid solubility allows fentanyl to cross the blood-cerebrospinal fluid barrier more rapidly and produce analgesic effects more quickly than morphine. This feature also allows fentanyl to accumulate in adipose and other lipid-rich tissue, through which redistribution can lead to prolonged respiratory depression and delayed recovery from sedation. Additionally, when the transdermal patch is removed, resorption of the residual drug through the skin continues for hours, and it takes approximately 17 hours for fentanyl blood levels to reduce by 50 percent. $^{2}$ For this, repetitive naloxone doses may be needed to treat acute intoxication.

Recently, there has been an increase in opioidrelated overdoses, including misuses and abuses of transdermal fentanyl patches. ${ }^{3}$ In order to prevent misuse, patients must be properly informed, and it must be confirmed that they have understood correctly. However, there is also a case report indicating that misuse is not related to sociocultural level. ${ }^{4}$ Fentanyl transdermal patches can be used by mistake because of their light and unpretentious imprints, with the assuming that they are heat patches or band-aids. ${ }^{4,5}$ For this reason, these drugs should be used under the clinician's control. Domestic use of opioids should also be strictly regulated. Additionally, medications and prescriptions must be individualized, and measures must be taken to monitor the excess medications of patients. This case underlines the need for strict precautions in the domestic use of opioids as well as transdermal fentanyl patches, in which misuse of opioid drugs can lead to critically toxic or lethal outcomes.

Hande Gurbuz Aytuluk, MD

Department of Anesthesiology and Reanimation University of Health Sciences Derince Training and Research Hospital Derince, Kocaeli, Turkey

Formerly

Department of Anesthesiology and Reanimation Kocaeli State Hospital Kocaeli, Turkey

\section{KEYWORDS}

Analgesics, intoxication, opioid, pain management, transdermal fentanyl 


\section{ACKNOWLEDGMENTS}

Special thanks to Dr. Sarpel Gurbuz for his help with preparation of this manuscript.Informed consent: Written informed consent was obtained from the patient included in the study.

\section{REFERENCES}

1. FDA issues updated safety warning regarding the inappropriate use of fentanyl transdermal (DURAGESIC) patches: Available at: $h t t p s: / / w w w . b c b s i l . c o m / p r o v i d e r / p d f / p d p \_u p d a t e s \_$ fda_0208.pdf.

2. Weaver JM: Multiple risks for patients using the transdermal fentanyl patch. Anesth Prog. 2014; 61(1): 1-2.
3. Coopman V, Cordonnier J, Pien K, et al.: LC-MS/MS analysis of fentanyl and norfentanyl in a fatality due to application of multiple Durogesic ${ }^{\circledR}$ transdermal therapeutic systems. Forensic Sci Int. 2007; 169(2-3): 223-227.

4. Voigt I: Fatal Overdose due to Confusion of a Transdermal Fentanyl Delivery System. Case Rep Crit Care. 2013; 154143.

5. Bakovic M, Nestic M, Mayer D: Death by band-aid: Fatal misuse of transdermal fentanyl patch. Int J Legal Med. 2015; 129(6): 1247-1252.

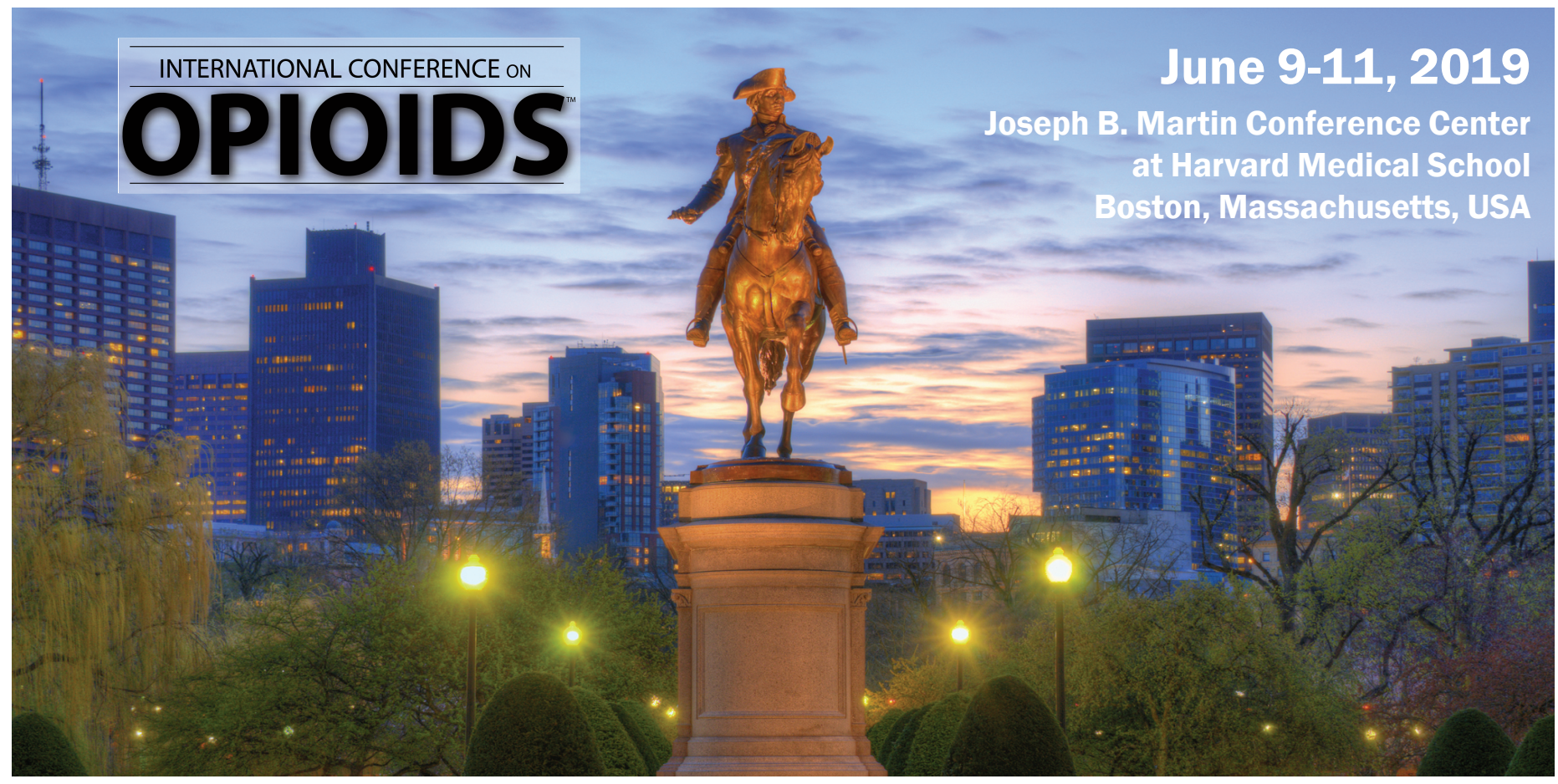

